\title{
FINAL REPORT Models of Geothermal Brine Chemistry
}

\author{
Grant: DE-FG07-93ID13247; Grant Period: 6/30/93-6/29/98 + Extension to 3/17/99 \\ P.I., Nancy M $\phi$ ller; Co P.I., John H. Weare \\ Chemistry Department (0340), University of California at San Diego, La Jolla, CA 92093
}

PROJECT BACKGROUND: Many significant expenses encountered by the geothermal energy industry are related to chemical effects. When the composition, temperature or pressure of the fluids in the geological formation are changed, during reservoir evolution, well production, energy extraction or injection processes, the fluids that were originally at equilibrium with the formation minerals come to a new equilibrium composition, temperature and pressure. As a result, solid material can be precipitated, dissolved gases released and/or heat lost. Most geothermal energy operations experience these phenomena. For some resources, they create only minor problems. For others, they can have serious results, such as major scaling or corrosion of wells and plant equipment, reservoir permeability losses and toxic gas emission, that can significantly increase the costs of energy production and sometimes lead to site abandonment. In future operations that exploit deep heat sources and low permeability reservoirs, new chemical problems involving very high $\mathrm{T}, \mathrm{P}$ rock/water interactions and unknown injection effects will arise.

The ability to predict chemical behavior and heat content for wide ranges of composition, temperature and pressure would enable the design of optimal operating strategies to minimize or avoid these adverse chemical effects. Predicting reservoir and energy production chemistry will become even more important as deeper, higher temperature geothermal resources, with very high development costs, are utilized to meet future energy needs. Unfortunately, predicting the chemistry of geothermal systems is difficult because of the variability and complexity of the solidliquid-gas equilibria controlling chemical behavior. These equilibria are complicated functions of the system's composition, temperature and pressure (XTP). These variables are different for different resources and can vary over time and from well to well in a single resource. Marked changes in XTP variables also occur during energy extraction from a specific site. Reliance on experimental data for estimating behavior is generally inadequate because the data pertain to a given set of variables and are often for relatively low temperature $\left(\sim 100^{\circ} \mathrm{C}\right)$ and pressure $(\approx 1 \mathrm{bar})$. The chemical complexity of geothermal systems makes the extrapolation of data to different conditions problematic. New laboratory simulations are time-consuming and costly, particularly at high temperature and pressure. Moreover, the very high temperatures and pressures of deep crustal and magma resources, where the bulk of the earth's heat is stored, are difficult or impossible to duplicate by current experimental methods.

Computer modeling technologies present the means to resolve these difficulties. Wellconstructed models, based on sound thermodynamic principles, can handle the complicated chemical reactions determining the behavior of geothermal energy production processes. They provide a means of succinctly summarizing large amounts of experimental data and of 
extrapolating to desired XTP conditions. Molecular level simulations can provide thermodynamic information in temperature and pressure regions inaccessible to present experimental methods. Incorporated into easy to use software, computer models can inexpensively provide reliable predictive capabilities for the industry.

With support from the DOE Geothermal Program, the UCSD Chemical Geology Group has carried out a research program to construct chemical models that accurately predict the chemical behavior of reservoirs, geothermal brines and their associated phases over wide ranges of composition, temperature and pressure. Our models are based on advances in physical chemistry theory that allow description of the thermodynamics of solids, liquids and gases via their free energy. These models can be used to improve the understanding of current $\left(\mathrm{T}=300^{\circ} \mathrm{C}\right)$ geothermal energy production processes (e.g., Mфller et al., 1998) as well as future energy extraction operations from deep, high temperature and pressure (e.g., Duan et al., 1995b) and low permeability heat sources. By providing important assessment tools for predicting heat content, scaling, breakout, steam fractions, gas emission, phase co-existence, miscibility, $\mathrm{pH}$, formation temperatures, etc., they can be used to significantly improve the productivity of geothermal operations. The free energy descriptions in both our subcritical $\left(\mathrm{T}=300^{\circ} \mathrm{C}\right)$ and supercritical models can be differentiated to produce models of heat properties for both regions. Since flexible computer models can easily and quickly simulate behavior under varying PVTX conditions, testing strategies to control unwanted behavior in active operations as well as forecasting the value of geothermal reservoirs as potential production sites is possible with this technology.

Parameterizing our phenomenological equations using experimental data provides a highly reliable representation of the equilibrium properties of complicated natural systems. To insure reliability, model construction and validation involves extensive comparison with experimental data. Model validation involves comparison of model predictions with data not used in parameter evaluation. Although these processes can be time-consuming, the benefits of having large amounts of experimental data summarized in a concise, easily transferable, equation format are considerable. In addition, the modeling process increases the applicability of many experimental data by providing a means to extrapolate information from limited composition, temperature, pressure experiments (e.g., boiling data in binary systems) to the more complex situations typical of natural fluids (e.g., boiling in multi-component systems).

For high T-P conditions where few data are available, we have developed new molecular based simulation technology (Duan et al., 1995a,c; 1996a) to generate reliable PVTX data. As we develop more theoretically based phenomenologies and better extrapolation techniques in the future, the amount of required data in model construction will be reduced and the region of extrapolation increased.

To facilitate the transfer of our modeling technologies, we have developed extensive user interface software so that our models can be bundled into easy-to-use application packages: TEQUIL (predicts scaling and reservoir chemistry as a function of composition for temperatures below $300^{\circ} \mathrm{C}$ ); GEOFLUIDS (predicts processes, such as flashing and miscibility, to high temperature, pressure conditions) and GEOHEAT (predicts enthalpies of complex mixtures). We have also developed an interactive Internet website: geotherm.ucsd.edu. The geothermal 
community and many researchers in other areas of interest access our modeling technology via this website.

PROJECT TECHNICAL OBJECTIVES: 1) To construct thermodynamic models for accurately predicting brine energetic and chemical behaviors and reservoir chemistry encountered in the extraction of energy from geothermal resources under a wide range of PTX conditions. (2) To develop new theoretically based modeling technologies that reduce the dependency on experimental data and increase the fundamental understanding of geothermal rock/water interactions. (3) To develop user interfaces and application software that facilitate the transfer and use of our model technologies. Specific project objectives are given in Table 1 below.

\section{Table 1: RESEARCH OBJECTIVES}

\section{CONSTRUCT MODELS FOR GEOTHERMAL ENERGY APPLICATIONS:}

-Predict the chemical behavior of complex brine-gas-solid systems for wide PTX ranges

-Predict heat properties of complex brines

-Develop molecular simulation technology to provide thermodynamic information for

PTX conditions with poor data availability

-Analyze theoretical extrapolation techniques to reduce the dependence on experimental data

-Simulate energy production chemistry

-Predict gas emission and scale formation

-Predict breakout and steam fractions

-Predict phase coexistence

-Understand injectate/rock chemistry

-Predict reservoir mineralogical reactions

-Predict behavior of deep hydrothermal fluids (supercritical conditions)

-Test strategies for abating chemical problems

-Characterize downhole thermodynamics

-Predict $\mathrm{pH}$

-Utilize computer capabilities to visualize chemical behavior

\section{EXTEND USEFULNESS OF EXPERIMENTAL DATA WITH MODELS}

-Identify and evaluate large amounts of experimental data in model parameterizations

-Provide standard for comparison of laboratory and field data

-Provide means of extrapolating data

-Summarize data in an easy to use and easily transferable format

\section{EXPAND TECHNOLOGY TRANSFER}

-Develop ancillary user interface software to facilitate use of modeling codes

-Incorporate models into application packages for PC use

-Provide a web site for interactive online use of modeling packages

-Develop visualization code that aids in the interpretation of model results

-Prepare modeling use instruction manuals

-Provide direct assistance to industry and geochemical research groups 
APPROACH: Utilizing advances in physical chemistry, we develop equation of state (EOS) descriptions of the thermodynamics of mixed natural fluid systems. This approach allows the construction of chemical models that yield highly useful information (e.g., solubilities, phase equilibria and heat properties) about geothermal reservoir behavior and energy production processes as a function of PTX. Our modeling approaches, based on fundamental theory of the liquid state, support accurate extrapolation and interpolation of the data used in the model parameterization.

For current, relatively near surface, geothermal operations ( $\left.\mathrm{P}^{\sim} 1 \mathrm{~atm}\right)$, the principal variation of the liquid density phase free energy is due to concentration changes of the solutes. For these conditions, we use modified Pitzer equations (1987) (see Solution Activity Equations, below) and laboratory measurements to construct models of complex rock-water-gas equilibria accurate to high concentration and temperature (Harvie and Weare, 1980; Harvie et al., 1984; Moller, 1988; Greenberg and Moller, 1989; Moller et al., 1998). In these equations, the coefficients, B, Z, ? , ?, etc., are parameters to be evaluated from data. In this approach, only binary and ternary data are necessary to fully parameterize a model for complicated higher component systems. Gas phases are easy to add because they act nearly ideally near 1 atm. Pressure corrections for low concentration applications can be calculated from the limiting partial molal volumes. These data are available. For higher concentrations, partial molal volumes as a function of composition are needed.

\section{Solution Activity Equations}

$$
\begin{aligned}
& \ln \gamma_{\mathrm{M}}=\mathbf{z}_{\mathrm{M}}^{2} \mathbf{F}+\sum_{\mathrm{a}} \mathbf{m}_{\mathrm{a}}\left(2 \mathbf{B}_{\mathrm{Ma}}+\mathbf{Z C}_{\mathrm{Ma}}\right)+\sum_{\mathrm{c}} \mathbf{m}_{\mathrm{c}}\left(2 \Phi_{\mathrm{Mc}}+\sum_{\mathrm{a}} \mathbf{m}_{\mathrm{a}} \psi_{\mathrm{Mca}}\right) \\
& +\Sigma_{\mathrm{a}} \Sigma_{\mathbf{a}<\mathrm{a}}, \mathbf{m}_{\mathrm{a}} \mathbf{m}_{\mathrm{a}}, \psi_{\mathrm{aa}}{ }^{\prime} \mathrm{M}^{+}+\mathbf{z}_{\mathrm{M}} \mid \Sigma_{\mathrm{c}} \Sigma_{\mathbf{a}} \mathbf{m}_{\mathrm{c}} \mathbf{m}_{\mathrm{a}} \mathbf{C}_{\mathrm{ca}} \\
& +\sum_{\mathbf{n}} \mathbf{m}_{\mathbf{n}}\left(2 \lambda_{\mathrm{nM}}\right)+\sum_{\mathbf{n}} \Sigma_{\mathbf{a}} \mathbf{m}_{\mathbf{n}} \mathbf{m}_{\mathbf{a}} \zeta_{\mathbf{n a M}}
\end{aligned}
$$

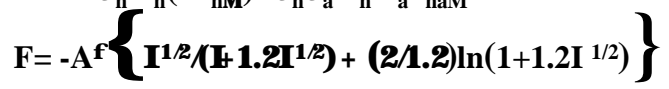

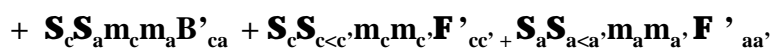

$$
\begin{aligned}
& \mathbf{B}_{\mathrm{ma}}=\beta^{(0)}{ }_{\mathrm{Ma}}+\beta^{(1)}{ }_{\mathrm{Ma}} \mathbf{g}\left(\alpha \mathbf{I}^{1 / 2}\right)+\beta^{(2)}{ }_{M a} \mathbf{g}\left(12 \mathbf{I}^{1 / 2}\right) \\
& \mathrm{g}(\mathbf{x})=\mathbf{2}\left(1-(1+\mathbf{x}) \mathrm{e}^{-\mathrm{x}}\right) / \mathbf{x}^{2}
\end{aligned}
$$

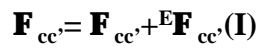

$$
\begin{aligned}
& \mathrm{C}_{\mathrm{ca}}=\mathrm{C}_{\mathrm{ca}}{ }^{\phi} / 2\left|\mathbf{z}_{\mathrm{c}} \mathbf{z}_{\mathrm{a}}\right|^{1 / 2} \\
& \mathbf{Z}=\Sigma_{\mathrm{i}} \mathbf{z}_{\mathrm{i}} \mid \mathbf{m}_{\mathrm{i}}
\end{aligned}
$$

\section{EOS for Compressible Phases}

$$
\begin{aligned}
& Z=\frac{P V}{R T}=Z^{h d}+Z^{d i p}+Z^{p e r} \\
& Z^{h d}=\frac{\left.1+\left[\frac{3 D E}{F}-2\right)\right] \eta+\left[\frac{3 E^{3}}{F^{2}}-\frac{3 D E}{F}+1\right] \eta^{2}-\frac{E^{3}}{F^{2}} \eta^{3}}{(1-\eta)^{3}} \\
& Z^{\text {dip }}=\eta \frac{\left[1-\frac{2 A_{3}}{A_{2}}\right] \frac{\partial A_{2}}{\partial \eta}+\frac{\partial A_{3}}{\partial \eta}}{\left[1-\frac{A_{3}}{A_{2}}\right]^{2}} \\
& Z^{p e r}=-\frac{1}{R T}\left[\frac{a}{v}+\frac{a c b}{2 v^{2}}+\frac{3 a d b^{2}}{16 v^{3}}+\frac{a e b^{3}}{16 v^{4}}\right]
\end{aligned}
$$

New problems are expected to arise in the future development of higher temperature, pressure reservoirs. Densities in the supercritical region are a strong function of pressure. To treat these systems and problems requiring density variation (e.g., miscibility, flashing, fluid inclusion studies, 2-phase flow in reservoirs), we have developed more advanced equations of state (EOS) that are able to describe systems with compressible phases. One of the approaches used is based on thermodynamic perturbation theory (Duan et al., 1995b) (see EOS for Compressible Phases, above). In these equations the parameters, A, B, D, a, etc, are established from data and polynomial mixing rules. ? and ? are functions of the molar volume. These new EOS descriptions 
yield free energies that are correct at liquid and vapor densities and can describe the large changes in composition and very high solute mole fractions that can occur during phase separation.

Semiempirical models, even when based on physical chemistry theory, require thermodynamic data for parameterization. Since there are much fewer experimental data available for model parameterization of high T, P systems, we have turned to molecular level approaches (e.g., molecular dynamics and Monte Carlo simulations) to meet this challenge and to generate needed thermodynamic information in other T-P ranges. We have shown (Duan et al., 1992d; 1995a,c; 1996a) that these approaches can be used successfully to generate the accurate thermodynamic information needed to model brine behavior to very high temperatures and pressures.

As our models are developed, they are incorporated into interactive software packages that facilitate their application to problems encountered by the geothermal community. Our present technology can be divided into four general modeling packages. (1) Aqueous solution models, based on the semiempirical electrolyte equations of Pitzer (see Pitzer (1987)), which can be used to predict liquid-solid-gas equilibria in dilute to concentrated brines up to high temperature $\left(\mathrm{T}=300^{\circ} \mathrm{C}\right)$. These models are incorporated into the application software package, TEQUIL. (2) Equation of state (EOS) models which can be used to calculate the PTX properties and vapor-liquid equilibria of natural fluids from subcritical to supercritical temperatures and pressures. These models are incorporated into the GEOFLUIDS application package. (3) First principle models, based on molecular dynamics (MD) and Monte Carlo (MC) simulations. These are particularly useful to generate the accurate thermodynamic data needed for developing EOS models which treat conditions that are difficult or impossible to simulate experimentally. (4) Heat content models, incorporating the aqueous solution and EOS technologies, which calculate specific heats and enthalpies for complex liquid-gas mixtures and allow predictions of such information as steam ratios, available heat and work. These models are incorporated into the GEOHEAT application package. Our software packages are available at no cost to the geothermal community to run on PCs and UNIX based computers.

We are also developing an interactive website which will expand the transfer of our technology. Even when summarized by models, the chemistry of geothermal systems is complicated. However, utilizing the interactive capabilities available over the Web, innovative visualization methods can be developed that will help users understand the complicated thermodynamic relationships that are responsible for brine behavior. A test website is now being prepared which has some of the TEQUIL models implemented (see Table 2). A TEQUIL User Manual, accessible from the site, is available.

\section{RESULTS/VARIANCES:}

TEQUIL Models: We have made considerable progress building a comprehensive suite of models for application to current, near surface geothermal operations $\left(\mathrm{T}<300^{\circ} \mathrm{C}\right)$ up to high brine 


\section{Table 2. TEQUIL MODELS (3/99)}

MODEL DESCRIPTION

\section{IMP $^{\mathrm{a}} \quad$ REF.}

Model: $\quad \mathrm{SiO}_{2}-\mathrm{NaCl}-\mathrm{KCl}-\quad$ Solubility of silca in brines, $0^{\circ} \mathrm{C}$ to $250^{\circ} \mathrm{C}, \quad$ yes $\quad \mathrm{MGW} 1998$

$\mathrm{MgCl}_{2}-\mathrm{CaCl}_{2}-\mathrm{H}_{2} \mathrm{O} \quad 1 \mathrm{~atm}$ - sat. pressure. Pitzer eq's.

Solubility of calcite in brines, sat. ratios,

Model: $\mathrm{Na}-\mathrm{K}-\mathrm{Ca}-\mathrm{HCO}_{3}-$

$\mathrm{CO}_{3}-\mathrm{HCl}-\mathrm{CO}_{2}-\mathrm{H}_{2} \mathrm{O}$

$\mathrm{CO}_{2}$ vapor/liquid equilibria, $\mathrm{pH}, 0^{\circ} \mathrm{C}$ to

yes $\quad$ MGW 1998

$250^{\circ} \mathrm{C} ; 1$ atm-sat pressure. Pitzer eq's.

EOS: $\mathrm{NH}_{3}-\mathrm{H}_{2} \mathrm{O}$

Densities $0-400^{\circ} \mathrm{C}, 1-1200$ bar Mixture:

no

DMW 1996b

$50^{\circ} \mathrm{C}$ and 1 bar to near critical T,P PVTX and phase equilibria

Model: Na-K-H-Ca-Mg- Solubility of salts in brines at $25^{\circ} \mathrm{C}, 1 \mathrm{~atm}$.

yes

HMW 1984 saturation ratios, activities, variable $\mathrm{pCO}_{2}$, pH. Pitzer eq's.

$\mathrm{CO}_{2}$

Model: Na-K-Ca-Mg-Cl$\mathrm{SO}_{4}-\mathrm{H}_{2} \mathrm{O}$

Low temperature solubility model, $25^{\circ}$ to yes

SMW 1990 $54^{\circ} \mathrm{C}$, saturation ratios, phase equilibria. Pitzer eq's.

Model: Na-K-Ca-Mg-Cl$\mathrm{SO}_{4}-\mathrm{H}_{2} \mathrm{O}$

Water-solid equilibria, $0^{\circ}$ to $250^{\circ} \mathrm{C}$, saturation ratios, phase transitions. Pitzer eq's.

a. Implemented in TEQUIL

concentrations. These TEQUIL models, which predict liquid/solid/gas equilibria as a function of brine composition and temperature, provide important tools for performance assessment (e.g., potential for flashing and scaling in power plants and well bores), predicting downhole chemistry and testing problem abatement strategies. Table 2 summarizes the status of the TEQUIL model package as of March 1999. The TEQUIL models implemented on the web site (see Table 2) include our $0-250^{\circ} \mathrm{C}$ model for calcite and amorphous silica scale and $\mathrm{CO}_{2}$ exchange, the HarveyMøller-Weare $25^{\circ} \mathrm{C}$ model (1984) of the complete seawater system, Na-K-H-Ca-Mg-Cl-OH-SO $\mathrm{HCO}_{3}-\mathrm{CO}_{3}-\mathrm{H}_{2} \mathrm{O}-\mathrm{CO}_{2}$, and the Spencer-Møller-Weare (1990) low temperature $\left(-55^{\circ}\right.$ to $\left.25^{\circ} \mathrm{C}\right)$ model of solid/liquid equilibria within the carbonate-free seawater system. The carbonate-free seawater system has also been modeled from $0^{\circ}-250^{\circ} \mathrm{C}$ (Møller, in prep). Application of the present TEQUIL package is illustrated below via solutions to selected problems encountered in the production of geothermal energy. 
The calcite scaling model in TEQUIL (see Table 2) predicts $\mathrm{CaCO}_{3}(\mathrm{~s})$ solubility as a function of brine composition to high ionic strength and to $250^{\circ} \mathrm{C}$. Table 3 compares geothermal well data for steam fractions and downhole calcium compositions (Ted DeRocher, personal communication; see also Duan et al., 1996d) with predictions of the model (together with results of the GEOFLUIDS and GEOHEAT models, see below).

\section{Table 3. Calcite Scale Prediction in a Geothermal Well}

\begin{tabular}{|l|c|c|c|c|c|}
\hline & $\begin{array}{c}\text { Steam } \\
\text { Fraction }\end{array}$ & $\begin{array}{c}\mathrm{CaCO}_{3} \mathbf{S R}^{\mathrm{a}} \\
\mathbf{W e l l h e a d} \\
\mathbf{T}=171^{\circ} \mathbf{C}\end{array}$ & $\begin{array}{c}\mathrm{CaCO}_{3} \mathbf{S R}^{\mathbf{a}} \\
\mathbf{W e l l h e a d} \\
\mathbf{T}=227^{\circ} \mathbf{C}\end{array}$ & $\begin{array}{c}\mathbf{C a C O}_{3} \mathbf{S R}^{\mathbf{b}} \\
\text { Wellhead } \\
\mathbf{T}=227^{\circ} \mathbf{C}\end{array}$ & $\begin{array}{c}\mathbf{C a}^{\circ} \text { Concentration } \\
(\mathbf{m})^{\mathbf{c}} \text { Well Bottom }\end{array}$ \\
\hline Measured & $9 \%$ & --- & --- & --- & .000243 \\
\hline Prediction & $12 \%$ & 0.39 & 2.2 & 0.3 & .000201 \\
\hline
\end{tabular}
a)Brine-CO2;
b) Brine+3183 ppm CO2(aq);
c)Antiscalent Conditions

The predicted steam fraction is calculated with the assumption of constant enthalpy expansion using GEOFLUIDS and GEOHEAT. The measured value is lower than predicted from this assumption, indicating a possible loss in heat to the formation. Using measured wellhead compositions and temperature $\left(171^{\circ} \mathrm{C}\right)$, we predict calcite undersaturation at the wellhead $(\mathrm{SR}=$ 0.39). At $227^{\circ} \mathrm{C}$ (the well bottom temperature), the wellhead brine would be supersaturated (SR $=2.2$ ) with respect to calcite due to the loss of $\mathrm{CO}_{2}$. In order to replicate the downhole conditions, we recombine the reported $\mathrm{CO}_{2}$ in the gas phase at the wellhead into the brine component. Now the brine is predicted to be undersaturated $(S R=0.3)$ at the downhole temperature. To reproduce downhole conditions in the presence of antiscalent, this brine was then re-equilibrated with the formation calcite. This results in a predicted well bottom $\mathrm{Ca}$ value of .000201. In Table 3, this value is compared to the measured value of .000243 taken in the presence of antiscalent. The higher measured concentration can be accounted for by the slightly elevated well bottom pressure ( 87 bars) which increases calcite solubility. The close agreement of observed and predicted results provides additional confidence in the application of the model to field geothermal problems.

Dissolved $\mathrm{SiO}_{2}$ concentration can be used as a silica geothermometer to estimate the downhole temperatures of geothermal formations. This technique, which is widely used in exploration, depends on the facts that the solubility of quartz is a function of temperature and that the residence time of formation waters is long enough to assume chemical equilibrium. 


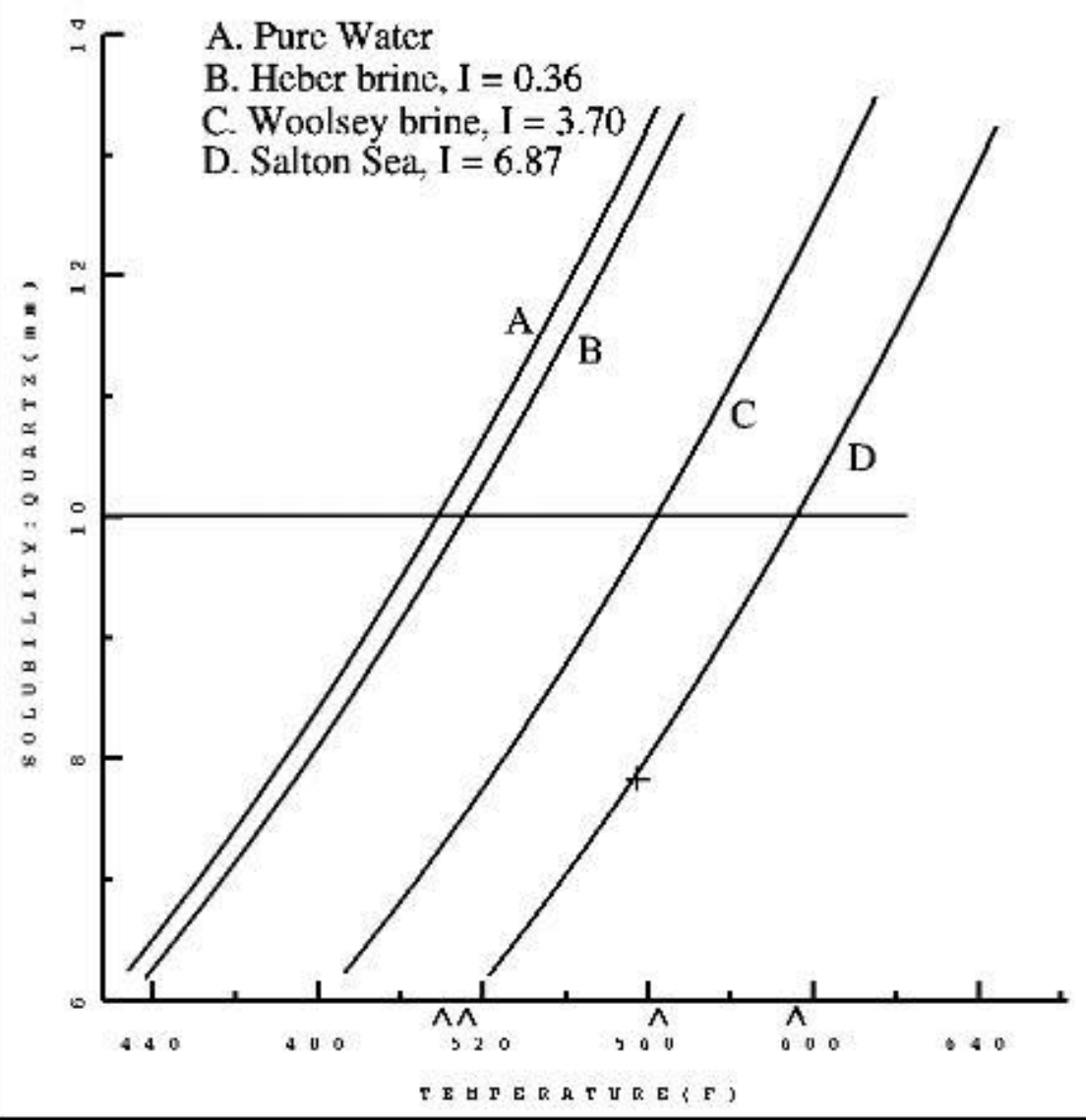

Figure 1: Solubility of quartz in brine.

The stable form of silica in most high temperature formations is quartz. Dissolution of quartz in water, according to the reaction:

$$
\mathrm{SiO}_{2} \text { (quartz) }+\mathrm{H}_{2} \mathrm{O}=\mathrm{H}_{4} \mathrm{SiO}_{4}(\mathrm{aq})
$$

yields $\mathrm{H}_{4} \mathrm{SiO}_{4}$, a very weak acid. Quartz solubility, like that of many minerals, decreases as the temperature is lowered. As a well is produced, the downhole fluid rises to the surface and undergoes a decrease in temperature and pressure. A significant temperature decrease would be expected to cause quartz to precipitate and lower the concentration of $\mathrm{H}_{4} \mathrm{SiO}_{4}$ in the brine. However, this does not occur for the $\mathrm{SiO}_{2}$ system because the rate of nucleation and precipitation of quartz is very slow. This feature makes the silica system an attractive candidate as a geothermometer.

The fact that the solubility of quartz is also a function of brine composition creates a problem for the prediction of downhole temperatures from $\mathrm{H}_{4} \mathrm{SiO}_{4}$ concentrations at the wellhead. 
Generally, neutral species are "salted out"; that is, they become less soluble as the salt concentration increases in the solution. This effect can be appreciable for concentrated brines (such as those found in the Salton Sea geothermal area). From the equilibrium relation for the solubility, Eq. (1), the effects of dissolved salt concentration can be expressed in terms of the activity coefficient for the $\mathrm{H}_{4} \mathrm{SiO}_{4}$ species in the solution. Assuming that $\mathrm{H}_{4} \mathrm{SiO}_{4}$ does not dissociate, these coefficients can be calculated for a wide range of brine conditions using the TEQUIL software. Results of such calculations are given in Fig. 1, above. In this figure, the horizontal line represents a hypothetical measured $\mathrm{H}_{4} \mathrm{SiO}_{4}$ concentration in a geothermal brine. The curves represent the calculated quartz solubility as a function of temperature for different brine compositions: A. in pure water; B. in the low concentration East Mesa brine; C. in the higher concentration Heber brine; and D. in the high concentration Salton Sea brine. From the figure, it can be seen that an error of $86^{\circ} \mathrm{C}$ would result if the pure water solubility curve was used instead of the Salton Sea curve to relate the $\mathrm{SiO}_{2}$ concentrations in the Salton Sea geothermal area to formation temperatures.

An additional compositional effect on the silica geothermometer reliability is the fact that boiling (breakout), caused by the pressure decrease as the brine moves up the well bore to the surface, also increases the concentrations of the dissolved species. This problem can be treated by the GEOHEAT software program and is discussed below.

GEOFLUIDS Models: Fluids containing $\mathrm{NaCl}, \mathrm{H}_{2} \mathrm{O}, \mathrm{CO}_{2}$ and $\mathrm{CH}_{4}$ as major components are commonly encountered in geothermal systems. The $\mathrm{CH}_{4}$ and $\mathrm{CO}_{2}$ species represent two of the most important insoluble gases in geothermal fluids, their presence greatly influencing the behavior of energy extraction processes (e.g., breakout characteristics of geothermal wells). Therefore, analysis of many problems associated with geothermal energy production operations requires the ability to predict the thermodynamic properties of this 4-component system as a function of composition, temperature and pressure. A major research goal for this grant period was to make substantial progress developing models for the $\mathrm{NaCl}-\mathrm{H}_{2} \mathrm{O}-\mathrm{CO}_{2}-\mathrm{CH}_{4}$ system that can treat a wide range of compositions, temperatures and pressures.

Previously, we constructed a model for predicting methane solubility in multicomponent geothermal brines $(0-6 \mathrm{~m})$ from $0^{\circ}$ to $250^{\circ} \mathrm{C}$ and from 0 to1600 bar (see Table 4, Duan et al., 1992c). This model incorporates Pitzer specific interaction phenomenology, parameterized by solubility data, to describe the liquid phase. The vapor phase is described by our EOS developed earlier (Duan et al., 1992a) for the pure $\mathrm{CH}_{4}, \mathrm{CO}_{2}$ and $\mathrm{H}_{2} \mathrm{O}$ species (Table 4) and by assuming ideal mixing of $\mathrm{H}_{2} \mathrm{O}$ and $\mathrm{CH}_{4}$. In this grant period, using a similar approach, we developed a model for the $\mathrm{H}_{2} \mathrm{O}-\mathrm{CO}_{2}-\mathrm{NaCl}$ system that is applicable to temperatures from $50^{\circ}$ to $300^{\circ} \mathrm{C}$ and for pressures from 0 to 1000 bar. A low temperature $\left(50^{\circ}-300^{\circ} \mathrm{C}\right)$ model for the 4-component $\mathrm{NaCl}-\mathrm{H}_{2} \mathrm{O}-\mathrm{CO}_{2}-\mathrm{CH}_{4}$ system was then constructed using the model we developed for mixtures in the $\mathrm{CO}_{2}-\mathrm{CH}_{4}-\mathrm{H}_{2} \mathrm{O}$ system (Table 4) (Duan et al. (1992b). Fig. 2 shows flashing pressures as a function of temperature calculated by this model for a typical geothermal fluid. Because these noncondensible gases are so insoluble, they make a large contribution to the flashing pressure even at low concentration. We note that for temperatures below $200^{\circ} \mathrm{C}$ their contribution is much larger than the contribution from the vapor pressure of water. Also note the strong effect of the presence of $\mathrm{CH}_{4}$ in the brine. Since $\mathrm{CH}_{4}$ is very insoluble, its contribution to the flashing pressure 
is large even when its concentration is low. In this approximation, the chemistry of other electrolytes is lumped into the $\mathrm{NaCl}$ variable. Note that this model assumes that $\mathrm{NaCl}$ is completed dissociated in the liquid phase and absent from the vapor phase. It is therefore limited to temperatures below approximately $300^{\circ} \mathrm{C}$.

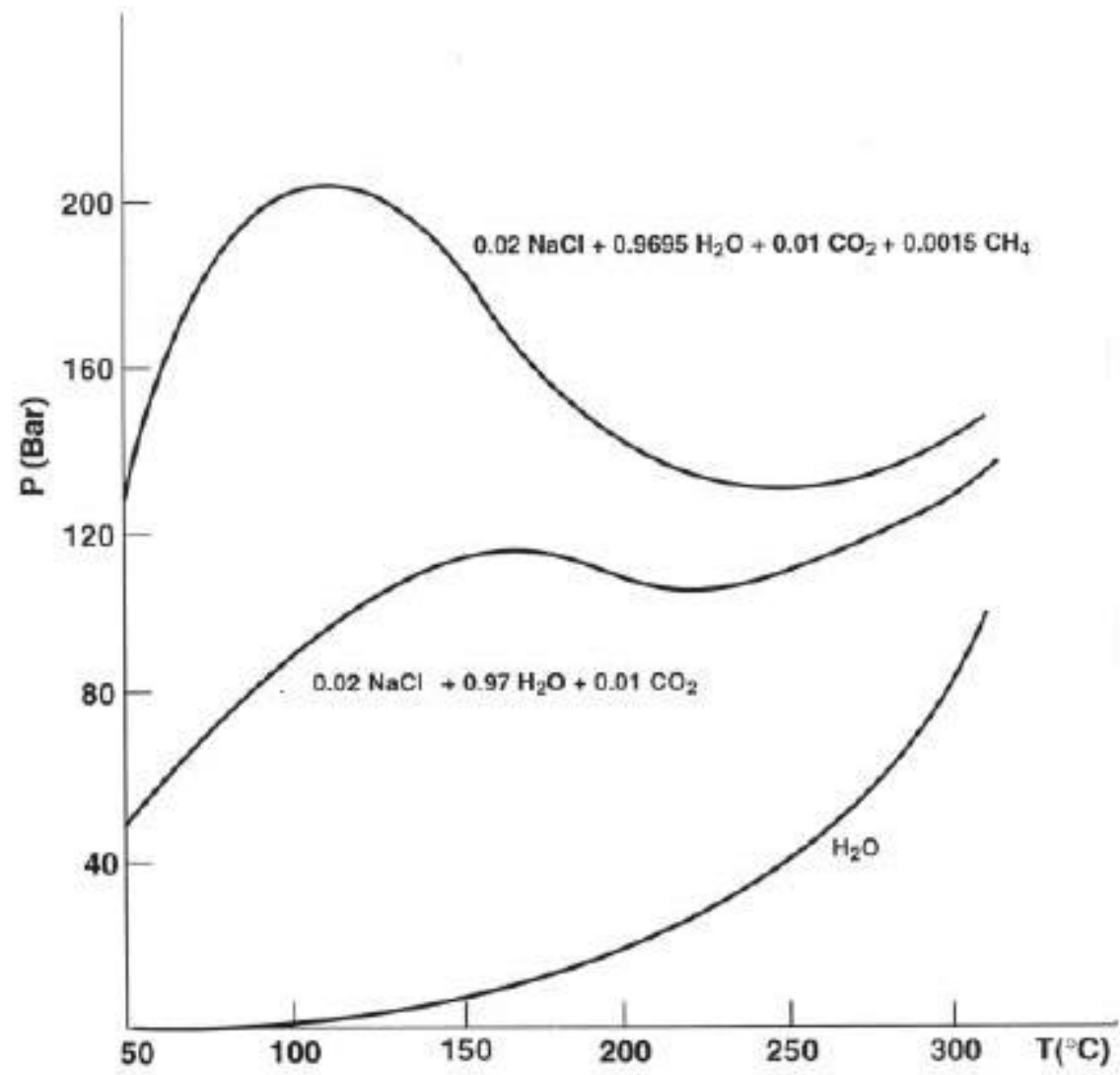

Figure 2: Breakout pressure for geothermal brines.

Our equation of state (EOS) modeling approach used for the low temperature $\mathrm{NaCl}-\mathrm{H}_{2} \mathrm{O}-$ $\mathrm{CO}_{2}-\mathrm{CH}_{4}$ model cannot be extended for temperature and pressure conditions above the critical point of water. The phenomenology used in the liquid density Pitzer-type models (discussed in the last section), cannot be generalized to arbitrary densities. Although the EOS for mixtures in the $\mathrm{CO}_{2}-\mathrm{CH}_{4}-\mathrm{H}_{2} \mathrm{O}\left(0^{\circ}-1000^{\circ} \mathrm{C} ; 0-8000\right.$ bar) (Duan et al., 1992b) handles variations in density, the addition of a salt end member, $\mathrm{NaCl}$, seemed impractical using this approach. Therefore, to incorporate compositional complexity into variable density models we had to explore different approaches that take into consideration the unique properties of the various subsystems in the $\mathrm{NaCl}-\mathrm{H}_{2} \mathrm{O}-\mathrm{CO}_{2}-\mathrm{CH}_{4}$ quaternary. 


\section{Table 4. GEOFLUIDS MODELS (3/99)}

\section{MODEL}

EOS: $\mathrm{CH}_{4}-\mathrm{CO}_{2}-\mathrm{H}_{2} \mathrm{O}$ (I)

Modified Lee-Kesler approach

EOS: $\mathrm{CH}_{4}-\mathrm{CO}_{2}-\mathrm{H}_{2} \mathrm{O}$ (II) Modified Lee-Kesler approach

EOS: $\mathrm{NH}_{3}-\mathrm{H}_{2} \mathrm{O}$

Model: methane solubility in brines

Model: $\mathrm{NaCl}-\mathrm{H}_{2} \mathrm{O}-\mathrm{CO}_{2-}^{-}$ $\mathrm{CH}_{4}$

Model: $\mathrm{H}_{2} \mathrm{~S}-\mathrm{NaCl}-\mathrm{H}_{2} \mathrm{O}$

EOS: $\mathrm{CH}_{4} \mathrm{CO}_{2} \mathrm{CO} \mathrm{N} \mathrm{N}_{2}$ $\mathrm{O}_{2} \mathrm{Cl}$ Lennard-Jones md sim. data and scaling

EOS: $\mathrm{H}_{2} \mathrm{O} \mathrm{CH}_{4} \mathrm{CO}_{2} \mathrm{CO}$ $\begin{array}{llllll}\mathrm{N}_{2} & \mathrm{O}_{2} & \mathrm{H}_{2} & \mathrm{H}_{2} \mathrm{~S} & \mathrm{Ar} & \mathrm{L}-\mathrm{J}\end{array}$ MD sim and scaling EOS: $\mathrm{CH}_{4}, \mathrm{~N}_{2}, \mathrm{O}_{2}, \mathrm{CO}_{2}$ EOS: $\mathrm{NaCl}-\mathrm{H}_{2} \mathrm{O}-\mathrm{CO}_{2}$ (a) EOS: (preliminary)
Mixtures, $50-1000^{\circ} \mathrm{C}, 0-1000$ bar

PVTX properties, phase equilibria

Densities $0-400^{\circ} \mathrm{C}, 1-1200$ bar Mixture: $50^{\circ} \mathrm{C}$ and 1 bar to near critical T,P PVTX and phase equilibria

Solubility $0-250^{\circ} \mathrm{C}, 0-1600 \mathrm{bar}, 0-6 \mathrm{~m} ; \mathrm{CH}_{4}-$ $\mathrm{CaCl}_{2}-\mathrm{H}_{2} \mathrm{O}: \quad 25^{\circ} \mathrm{C}-125^{\circ} \mathrm{C} ; \mathrm{CH}_{4}-\mathrm{Na}-\mathrm{K}-\mathrm{Mg}-\mathrm{Ca}-$ $\mathrm{Cl}-\mathrm{SO}_{4}-\mathrm{HCO}_{3}-\mathrm{CO}_{3}-\mathrm{H}_{2} \mathrm{O}: 25^{\circ} \mathrm{C}$ EOS for vapor phase chemical pot. and Pitzer eq's. for liquid phase chemical potential

no

DMW 1996b

no

DMGW 1992c

Solubility $50-300^{\circ} \mathrm{C}$; 0-1000 bar. Use DMGW 1992c approach and DMW1992b for $\mathrm{CH}_{4}$ $\mathrm{CO}_{2}-\mathrm{H}_{2} \mathrm{O}$ mixtures

Solubility of $\mathrm{H}_{2} \mathrm{~S}$ in $\mathrm{NaCl}$ aqueous systems, 0$320^{\circ} \mathrm{C}$, 1-300bar and 0-6m NaCl. EOS for vapor phase chemical potential and Pitzer eq's. for liquid phase chemical potential

Pure nonpolar and weakly polar species, supercritical to $2000 \mathrm{~K}$ and 20,000 bar, PVTX properties, No phase equilibria

Extend above to polar $\mathrm{H}_{2} \mathrm{O}$ and to binary mixtures, supercritical to $2000 \mathrm{~K}$ and $0-25,000$ bar, PVTX, No phase equilibria

Shows that 1992c EOS can be used to construct phase diagrams using MD simulated data in liquid/vapor coexistence range and Maxwell constructions

Pure systems and binary aqueous salt mixtures, 300-1000 ${ }^{\circ}$; 0-6000bar, PVTX, phase equilibria. Modified Anderko-Pitzer perturbation approach

DMW 1996c

DMW 1992c

no

DMW 1996a

no

DMW 1995a

yes

DMW 1995b

Modified Anderko-Pitzer perturbation no approach 
This grant period considerable effort was spent developing variable density models for the salt-containing ternaries: $\mathrm{NaCl}-\mathrm{H}_{2} \mathrm{O}-\mathrm{CO}_{2}\left(>300^{\circ}-1000{ }^{\circ} \mathrm{C} ; 0-6000\right.$ bar) (Duan et al., 1995b) and $\mathrm{NaCl}-\mathrm{H}_{2} \mathrm{O}-\mathrm{CH}_{4}$. Our approach generalizes the model of the $\mathrm{NaCl}-\mathrm{H}_{2} \mathrm{O}$ system developed by Anderko and Pitzer (1993) that is related to the earlier approach of Dimitrelis and Prausnitz (1986). Extensive evaluation of the $\mathrm{NaCl}-\mathrm{H}_{2} \mathrm{O}$ system led us to the conclusion that the hard sphere and dipolar terms used by Anderko and Pitzer are needed for a reasonable description of the $\mathrm{NaCl}$ $\mathrm{H}_{2} \mathrm{O}$ data to high temperature and pressure. To treat mixtures in the $\mathrm{NaCl}-\mathrm{H}_{2} \mathrm{O}-\mathrm{CO}_{2}$ and $\mathrm{NaCl}-$ $\mathrm{H}_{2} \mathrm{O}-\mathrm{CH}_{4}$ systems, this forced us to adopt a form similar to the Anderko-Pitzer EOS for the less polar binaries involving $\mathrm{CO}_{2}$ and $\mathrm{CH}_{4}$. Therefore, rather than incorporating our already tested EOS for the $\mathrm{CO}_{2}-\mathrm{CH}_{4}-\mathrm{H}_{2} \mathrm{O}$ system (Duan, Møller and Weare (1992b), we used the formulism of Anderko and Pitzer to add $\mathrm{CO}_{2}$ and $\mathrm{CH}_{4}$ to the $\mathrm{NaCl}-\mathrm{H}_{2} \mathrm{O}$ model (see Duan et al., 1995b). A preliminary 4-component model is completed.

The development of the EOS is based on the Holmholtz free energy. The system is first idealized as a system of molecules (e.g., $\mathrm{NaCl}, \mathrm{H}_{2} \mathrm{O}, \mathrm{CO}_{2}, \mathrm{CH}_{4}$ ) interacting with intermolecular potentials for which an approximate Helmholtz free energy can be calculated from statistical mechanics. The theoretical forms assumed for this "reference system" are then corrected to incorporate the behavior of the real system. The corrections are empirical, but chosen to retain the limiting behavior. The parameters in the resulting equations are evaluated from both PVXT data and phase equilibria data. The detailed equations describing the parameterization of these equations for the NaCl- $\mathrm{H}_{2} \mathrm{O}$ system are very complicated and are given in Anderko and Pitzer (1993) and Duan, Møller and Weare (1995b). We point out that the $\mathrm{NaCl}-\mathrm{H}_{2} \mathrm{O}-\mathrm{CO}_{2}$ (Duan et al., 1995b) and $\mathrm{NaCl}-\mathrm{H}_{2} \mathrm{O}-\mathrm{CH}_{4}$ models are only applicable above $300^{\circ} \mathrm{C}$ because the $\mathrm{NaCl}$ species is assumed to be associated. Our earlier model of the salt-free $\mathrm{CO}_{2}-\mathrm{CH}_{4}-\mathrm{H}_{2} \mathrm{O}$ system (1992b), which is also included in the GEOFLUIDS package, is applicable to lower temperature systems $\left(50^{\circ}\right.$ to $1000^{\circ} \mathrm{C}$ and 0 to 1000 bar).

The ternary EOS models form the base for constructing an EOS for the quaternary $\mathrm{NaCl}$ $\mathrm{H}_{2} \mathrm{O}-\mathrm{CO}_{2}-\mathrm{CH}_{4}$ system that can treat variable density. These models are very important for many geothermal calculations (e.g., boiling pressure (see Fig. 3), gas fugacity, solubility, volumetric properties, densities, etc.) in mixed gas-brine systems. We believe that our models are the only ones available that are able to predict phase equilibria and PVTX properties in these systems over such broad T-P ranges. These capabilities are essential to predict the behavior of geothermal systems undergoing phase separation and density and compositional changes due to significant alterations of temperature and pressure. These conditions can occur during brine extraction (e.g., flashing) and reinjection as well as during the evolution of the resource when brines are cycled through high temperature and pressure regions in the formation. 
GEOHEAT Models: Accurate estimates of the available heat in the working fluid are essential for the economic exploitation of a geothermal resource. Unfortunately, with the exception of the pure water system, there are very few enthalpy data for the temperatures and pressures of geothermal operations. Therefore it is common in the industry to use pure water enthalpy information to predict fluid behavior (e.g., prediction of steam fractions). However geothermal fluids are typically solutions with high concentrations of ionic species and insoluble gases. The enthalpy of such solutions is a complex function of composition, temperature and pressure. As a result, predictions of important geothermal information from pure water enthalpies can have significant errors.

Since the models in TEQUIL and GEOFLUIDS are based on the free energy of a system, all other thermodynamic properties, including heat properties (specific heat, heat of solution and enthalpy) of complex brine/gas mixtures, can be derived by the appropriate derivatives. However, in order for heat model development to be successful it is generally necessary to include some heat data in the database for the parameterization of the free energy. We have developed models of brine and gas phase enthalpies using this approach. Because the relation between the free energy and the enthalpy is maintained, these models produce consistent predictions of heat properties and other temperature dependent properties related to the free energy (e.g., the solubility of scaling minerals, the temperature dependence of phase coexistence). Using this approach, an enthalpy model $\left(50^{\circ} \mathrm{C}\right.$ to about $\left.2000^{\circ} \mathrm{C}\right)$ of the $\mathrm{CO}_{2}-\mathrm{CH}_{4}-\mathrm{H}_{2} \mathrm{O}$ system was developed that is based on our free energy model for this system (Duan et al., 1992a,b).

There are very few enthalpy data for the complete $\mathrm{NaCl}-\mathrm{H}_{2} \mathrm{O}-\mathrm{CO}_{2}-\mathrm{CH}_{4}$ system, and a single modeling approach that extends from low temperatures $\left(50^{\circ} \mathrm{C}\right)$ to high temperatures $\left(>300^{\circ} \mathrm{C}\right)$ is not yet available for the salt containing systems. Therefore, a method to calculate enthalpy in the $\mathrm{NaCl}-\mathrm{H}_{2} \mathrm{O}-\mathrm{CO}_{2}-\mathrm{CH}_{4}$ system can be developed that is based on the assumptions:

1. for salt free systems, we can use the $\mathrm{H}_{2} \mathrm{O}-\mathrm{CO}_{2}-\mathrm{CH}_{4}$ enthalpy model to calculate the enthalpy for all temperatures above $50^{\circ} \mathrm{C}$.

2. for the gas phases in salt containing systems, we can use the enthalpy calculated from our model of the $\mathrm{H}_{2} \mathrm{O}-\mathrm{CO}_{2}-\mathrm{CH}_{4}$ system for temperatures below $300^{\circ} \mathrm{C}$.

3. for the liquid phase in salt containing systems, we can use the enthalpy calculated from the $\mathrm{NaCl}-\mathrm{H}_{2} \mathrm{O}$ model of Pitzer et al. (1984) for temperatures below $300^{\circ} \mathrm{C}$.

4. for salt containing system above $300^{\circ} \mathrm{C}$, we can estimate (due to the lack of heat data) the enthalpy by differentiating our perturbation theory EOS for the complete system. This model can be used both for the dense fluid and vapor phases.

Given the pressure, temperature and composition of a fluid in the $\mathrm{NaCl}-\mathrm{H}_{2} \mathrm{O}-\mathrm{CO}_{2}-\mathrm{CH}_{4}$ system, for temperatures below $300^{\circ} \mathrm{C}$ we can use the GEOFLUIDS NaCl- $\mathrm{H}_{2} \mathrm{O}-\mathrm{CO}_{2}-\mathrm{CH}_{4}$ model (Table 4; EOS for vapor phase chemical potential and Pitzer eq's. for liquid phase chemical potential) to determine if there is a phase separation (liquid-vapor coexistence). If there is, this GEOFLUIDS model can calculate the amount of the phases (liquid and vapor) and their compositions. Above $300^{\circ} \mathrm{C}$, we use the perturbation theory model for the $\mathrm{NaCl}-\mathrm{H}_{2} \mathrm{O}-\mathrm{CO}_{2}-\mathrm{CH}_{4}$ system (Table 4; modified Anderko-Pitzer approach) for these calculations. With this information, we can estimate accurately the total enthalpy of the system using the enthalpy models for the separate phases as above. This information can be plotted on an enthalpy pressure diagram (with 
enthalpy and pressure as variables). It is still difficult to determine the pressure for any given enthalpy but this can be done graphically. Presently, GEOHEAT includes the $\mathrm{CO}_{2}-\mathrm{CH}_{4}-\mathrm{H}_{2} \mathrm{O}$ model.

In Fig. 3, we have constructed an enthalpy/mol vs. pressure diagram for a brine similar in composition to that of the Salton Sea geothermal field. Note that the solid lines represent the isotherms. For a multicomponent system such a diagram is dependent on the total composition.

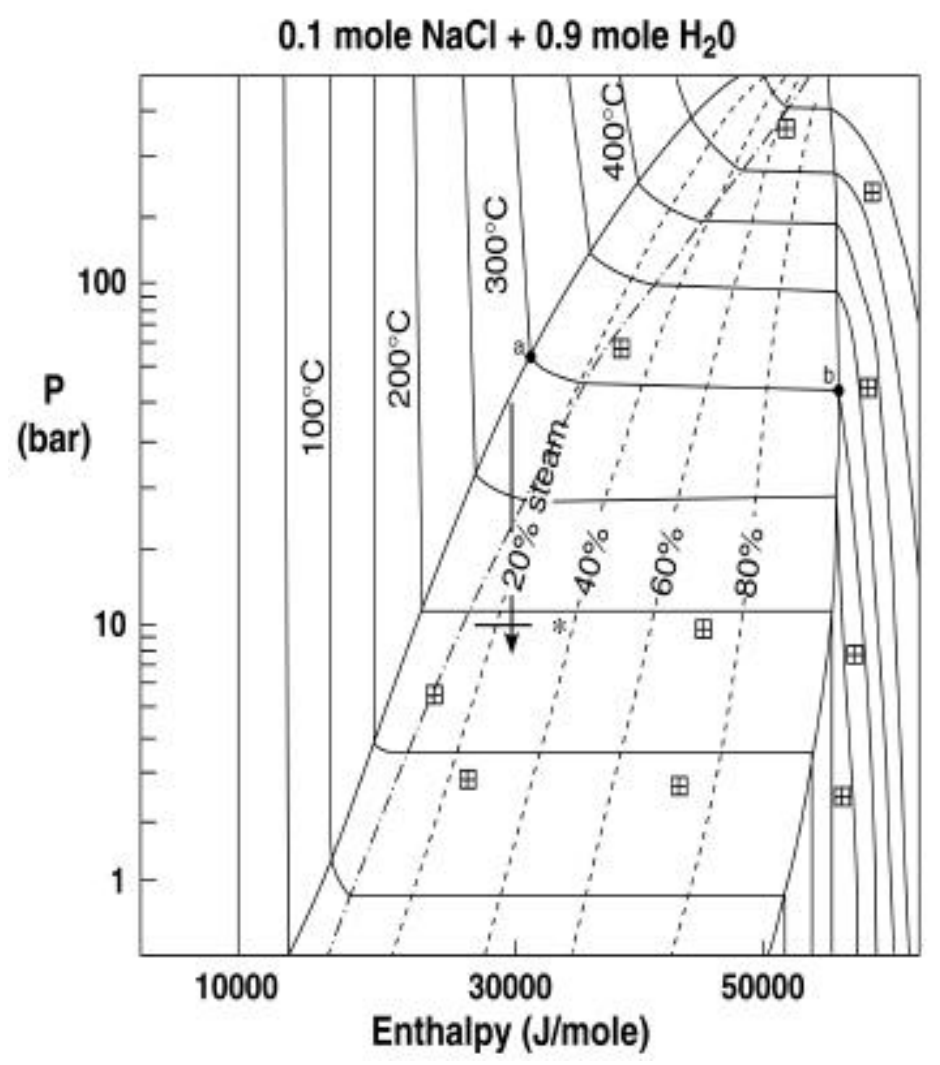

Figure 3: Enthalpy-Pressure diagram for a Salton Sea-like brine.

In this calculation, we have lumped the entire brine solute composition into the $\mathrm{NaCl}$ concentration. For subcritical systems, liquids (lower enthalpy systems) are present on the left of the diagram and gases (higher enthalpy systems) on the right. Considering the $300^{\circ} \mathrm{C}$ isotherm as an example, we can see that at high pressure the enthalpy is fairly constant with pressure drop. This is because the enthalpy change with pressure in a liquid density system at constant temperature is relatively small. At some pressure, the system will flash and the enthalpy change related to the formation of steam becomes large. For this temperature and composition, flashing occurs at 67 bars, point (a) in the $300^{\circ} \mathrm{C}$ isotherm. This pressure is a little lower than it would be for pure water ( 87 bars) because the vapor pressure of the fluid is lowered by the dissolved salt. 
On the diagram, the two phase region is separated from the single phase region by a solid line. Point (a) on the diagram for the $300^{\circ} \mathrm{C}$ isotherm is the enthalpy of the liquid at the bubble point. As the pressure is lowered below that of point (a), more water is evaporated. Since the composition of the liquid and vapor are changing, the total enthalpy/mol in the coexistence region has a curvature. At some point in this system solid $\mathrm{NaCl}$ precipitates. When this occurs, the vapor pressure and the solubility (concentration in the liquid phase) of the system are fixed. With continued evaporation, the liquid is then removed from the system along the horizontal line. When the liquid disappears, the pressure again drops at constant $\mathrm{T}$. The enthalpy/mol of the vapor coexisting with the liquid and the solid at $300^{\circ} \mathrm{C}$ (and along the coexisting liquid/vapor/solid line) is represented on the diagram by point (b).

Fig. 3 also includes mole \% steam lines (dashed lines). These lines, which give the steam ratio for a particular isotherm, are especially useful for geothermal applications. All this information may be calculated from the GEOHEAT and GEOFLUIDS software.

As an application of the diagram shown in Fig. 3, reconsider Fig. 1. The measured well head brine silica composition in this figure is represented by the horizontal line. To use the silica geothermometer approach for estimating the downhole temperature, we must be able to reconstruct the downhole brine concentrations. Therefore, we need to correct this wellhead composition to compensate for the loss of water due to evaporation during production. An interactive process would be required to get a precise answer. Here, we will only look at one cycle. Suppose that the uncorrected composition gives a downhole temperature of $300^{\circ} \mathrm{C}\left(572^{\circ} \mathrm{F}\right)$ from the geothermometer (see Fig. 1 for a Salton Sea brine). Take that as an initial estimate of the temperature and assume that the fluid at the bottom of the well is at the bubble point (point (a) on the diagram in Fig. 3). We can now ask how much a fluid at $300^{\circ} \mathrm{C}$ evaporated while moving up the well bore, assuming that the motion of the fluid up the well bore is a constant enthalpy process (see the arrow in Fig. 3). Fixing the wellhead pressure at 10 bar, we see that the constant enthalpy line intersects the 10 bar line at a breakout of roughly $23 \%$ steam. We can now use this information to approximately correct the wellhead composition and recalculate the data of Fig. 1. Diluting the measured wellhead concentration of $\mathrm{H}_{4} \mathrm{SiO}_{4}$ to reflect the loss of water due to evaporation, we recalculate the bottom hole temperature (indicated on Fig. 1 by a cross). Note that the new temperature of $\left(558^{\circ} \mathrm{F}\right)$ is $38^{\circ} \mathrm{F}$ less than the first estimate (Table $\left.5,596^{\circ} \mathrm{F}\right)$. 


\section{Table 5: Steam Separation Properties for Pure Water vs. the $\mathrm{NaCl}-\mathrm{H}_{2} \mathrm{O}$ System}

$\begin{array}{lcccr}\text { System } & \text { SR } & \text { Wellhead T (F) } & \text { Wellhead P } & \text { Quartz T (F ) } \\ \text { Pure Water } & 0.29 & 174(345) & 10 \mathrm{bar} & 453(510) \\ \text { Brine }(6.87 \mathrm{~m}) & 0.23 & 188(370) & 10 \mathrm{bar} & 558(596)\end{array}$

Recalculated values for important well properties are summarized in Table 5. As expected, the wellhead steam ratio (SR) at fixed wellhead pressure is less for the brine than for pure water. This decrease in evaporation is also reflected in the higher wellhead temperature of the brine.

Molecular Simulation Studies: When possible our models are based on high quality laboratory measurements. However, the ranges of composition, temperature and pressure variables that can be encountered in present day and future geothermal applications are extremely large. It is unlikely that sufficient data to completely parameterize models covering these ranges will ever exist. Furthermore, while there has been progress in the development of appropriate equations to describe the thermodynamics of complex aqueous mixtures, there is still much we don't know about solutions at high temperatures and pressures. Therefore, one of our research goals is to develop first principles and molecular based technologies that can be used to generate both accurate thermodynamic data and equations that better represent behavior at high temperatures and pressures.

The results of our molecular dynamics (MD) and Monte Carlo (MC) simulations have been very positive (Duan et al. 1992d; 1995a,c; 1996a). Our EOS model of the $\mathrm{CH}_{4}-\mathrm{CO}_{2}-\mathrm{N}_{2}-\mathrm{H}_{2} \mathrm{O}$ system (1996a) for high temperatures and pressures was generated from PVT data (see Table 4). Recent comparisons of model predictions with new experimental data have shown it to be considerable more accurate than other competing EOS. Simulations are more difficult for brine systems. However, the results of our 1-1 electrolyte $(\mathrm{NaCl}$ and $\mathrm{KCl})$ simulations, which use a simple parameterization of the intermolecular potentials, have accuracies close to that of experiments for a large range of $\mathrm{T}$ and $\mathrm{P}$, both above and below the critical values for water.

We have also begun a study to quantify the accuracy of simulation-based water thermodynamics. The most important data for geological applications involve the free energy of aqueous systems (e.g., phase equilibria). A system's free energy is very difficult to simulate because this involves integration over intensive variable changes from a known state (e.g., ideal gas) to the state of interest. To do this requires many simulation points. Although a great deal of experimental thermodynamic data exist for the pure water system, few simulation studies have 
focused on comparing free energy predictions. We have made good progress using our Watts water potential (Duan et al., 1995c). We have shown that this potential provides higher quality predictions of properties (such as enthalpy, liquid structures, etc.) than other models of water interactions. Preliminary calculations, however, suggest that there may be some problems in the prediction of liquid-vapor coexistence even with this highly accurate model. We are presently trying to solve these problems. When completed, this study will be highly valuable for estimating errors in the simulated properties of aqueous systems for geothermal applications.

Website Development: The calculations that have been reported above can all be done with the software available from our group. We will continue to offer diskette-based software. However, we are in the process of developing an interactive website that will incorporate the present models as well as provide new functionality. By having this software on the internet, updates of the models will immediately be available to users. In addition, we have initiated development of a postprocessing package called GEOPHASES, which will compile and process data from the other application packages.

In Fig. 4, we show a phase diagram for the 5-component system, $\mathrm{Na}-\mathrm{K}-\mathrm{Mg}-\mathrm{Cl}-\mathrm{SO}_{4}-\mathrm{H}_{2} \mathrm{O}$, computed as a function of temperature with a preliminary version of GEOPHASES. Charge balance implies that there are four degrees of freedom when $\mathrm{T}$ and $\mathrm{P}$ are fixed. Obviously, the general phase relations for this system cannot be drawn on a three dimensional diagram. However, the dimensionality may be reduced by plotting only certain regions of the diagram. For example, in the projection shown in Fig. 4 all phases coexist with solid $\mathrm{NaCl}$. To construct this figure, the TEQUIL solubility models are used to calculate brine compositions in equilibrium with all the invariant mineral assemblages throughout the $0^{\circ}$ to $250^{\circ} \mathrm{C}$ temperature range. Obtaining this large number of calculated "data" points and then drawing the polythermal phase diagram by hand is a daunting task. GEOPHASES will automatize this process. The GEOPHASES software will both direct computations and construct the appropriate projections. 


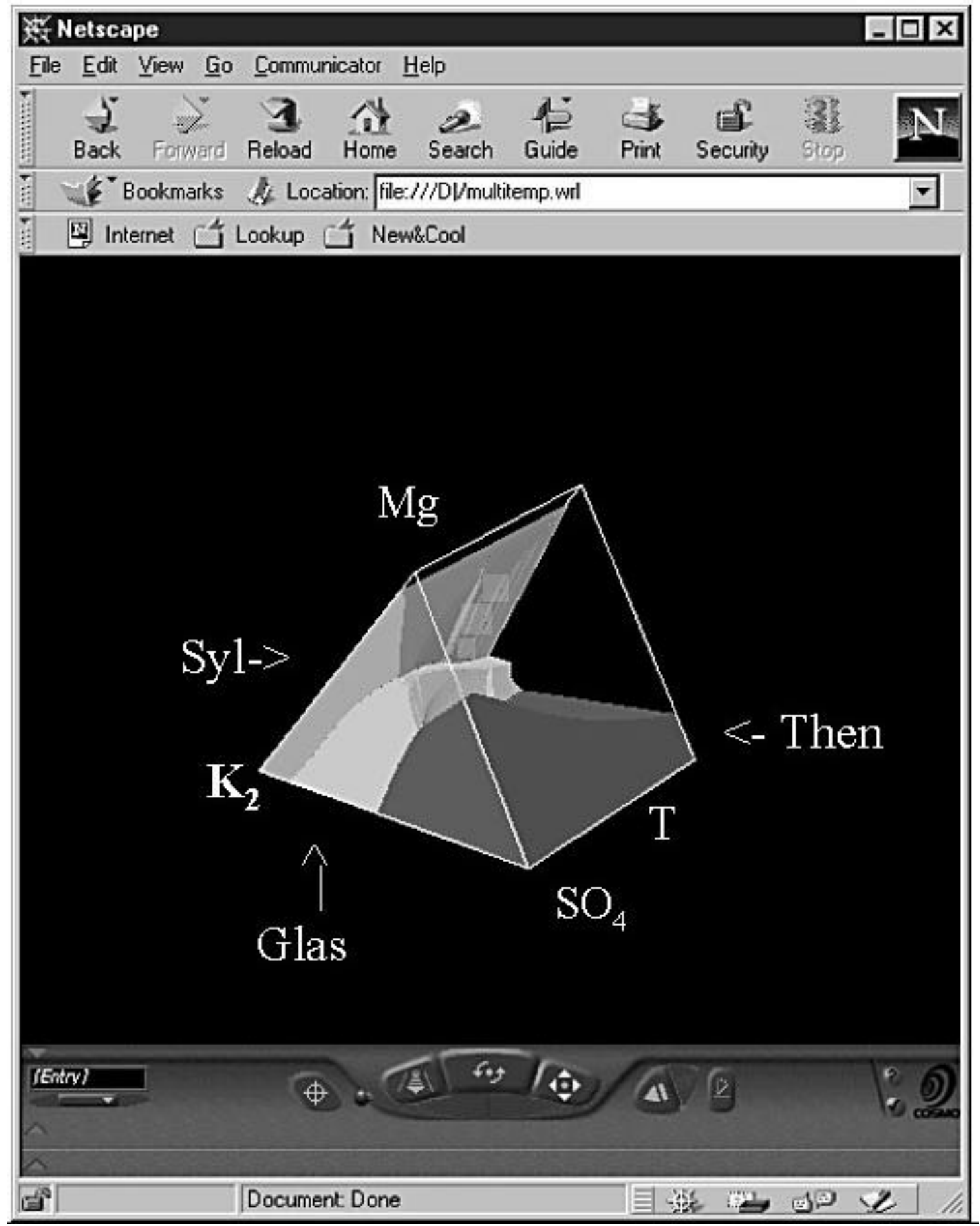

Figure 4: Phase diagram of the $\mathrm{Na}-\mathrm{K}-\mathrm{Cl}-\mathrm{SO}_{4}-\mathrm{H}_{2} \mathrm{O}$ system (in equilibrium with halite) as a function of temperature. 
TECHNOLOGY TRANSFER:

Selected Contacts (requests for models \& information) During Grant Period:

ARMY CORPS. OF ENGINEERS

ASPENTEC, Cambridge, MA

BEN HOLT COMPANY, Pasadena CA.

BHP MINERALS

CANADIAN POTASH OF SASKATCHEWAN:

CAL ENERGY INTERNATIONAL, LTD.

CARNEGIE INSTITUTION, Geophysical Laboratory, Washington, D.C

CFTA, Palermo, Italy

CREGU/CNRS, France

DEPARTMENT OF PETROLEUM ENGINEERING, HERIOT-WATT UNIVERSITY, Scotland DOW CHEMICAL CO.

ENEL, Italy

ENERGETSKI INSTITUT, Croatia

EXXON

GEOFORSCHUNGS ZENTRUM, Potsdam, Germany

GEOSCIENCE, LTD., UK

GEOTHERMAL RESOURCE CENTER, Miravalles Geothermal Field

GEOTHERMEX

GOETTINGEN UNIVERSITY

HARVARD UNIVERSITY

HERIOT-WATT UNIVERSITY, Scotland

HYUNDAI ENGINEERING COMPANY, Seoul, Korea: geothermal applications

INDUSTRIAL RESEARCH, LTD., New Zealand

INEL

INSTITUTE FUR TIEFLAGERUNG, Germany.

INSTITUTO INVESTIGACIONES ELECTRICAS, Cuernavaca, Mexico

JMC GEOTHERMAL CO., JAPAN

KLUWER PUBLICATIONS: Requested review of chapter: "A Model for deep Geothermal Brines, I: T-P-X State-Space Description.

KOREA INST. OF SCIENCE AND TECHNOLOGY

LEYTE GEOTHERMAL POWER PROJECT, Philippines

LOS ALAMOS NATIONAL LABORATORY, reinjection data from Dixie Valley

MAGMA OPERATING COMPANY

MANCHESTER UN, Earth Science Dept.

MASSEY UNIVERSITY, New Zealand

McGILL UNIVERSITY, CANADA, Geosciences Dept.

MONTEREY AQUARIUM RESEARCH INSTITUTE

LAWRENCE LIVERMORE LABORATORY.

LOS ALAMOS NATIONAL LABORATORY.

NUCLEAR REGULATORY COMMISSION

OAK RIDGE NATIONAL LABORATORIES

OBSERVATORIA NACIONAL-CNPQ (Brazil) 
ORME GEOTHERMAL, INC.

OXBOW GEOTHERMAL

PACIFIC NORTHWEST LAB.

PARADIS, Ray, Geothermal Consultant, Reno, NV

PG\&E

SC\&A: geothermal studies

SCRIPPS INSTITUE OF OCEANOGRAPHY

SHELL EXPO, Aberdeen, Scotland

SINICA CHINA GEOLOGICAL INST., Taiwan.

SOLID CHEMICALSOLUTIONS, Netherlands

SOLAR GAS TURBINES

STANFORD UNIVERSITY, Geology Department

ST. FRANCIS UN., CANADA.

SOUTHWEST INSTITUTE

TECHNICAL UNIVERSITY, POLAND

TECHNISCHE UNIVERSITAT, Berlin, Germany.

TECHNISCHE UNIVERSITAT BERGAKADEMIE, Freiberg, Germany.

TRUESDELL, AL, geothermal consultant

UNION CARBIDE CORP.

UNIVERSITA DEGLI STUDI DI PALERMO

UNIVERSITAT BREMEN

UNIVERSITAT FREIBERG, Germany

UNIVERSITY OF AUCKLAND, New Zealand

UNIVERSITY OF CALIFORNIA, BERKELEY

UNIVERSITY OF CHICAGO, DEPARTMENT OF GEOPHYSICAL SCIENCE

UNIVERSITY OF GUANAJUATO, Mexico

UNIVERSITY OF ILLINOIS

UNIVERSITY OF MICHIGAN:

UNIVERSITY OF NANCY, France

UNIVERSITY OF NANJING

UNIVERSITY OF NEW MEXICO

UNOCAL, Texas

US ARMY COLD REGIONS RESEARCH AND ENGINEERING LABORATORY

USGS

UURI

VIRGINIA POLYTECHNICAL INSTITUTE

YANKEE/CAITHNESS

Selected Technical Meetings/Presentations During Grant Period:

Potash Corporation Workshop, Saskatchewan, Canada, Nov. 18, 1993.

DOE Geothermal Program review, San Francisco, CA, April 25, 1994.

Pan-American Fluid Inclusion Study Meeting, Mexico City, Mexico, May 18-22, 1994.

Annual Calorimetric Conference, New Mexico, August, 1994.

UURI Geothermal Energy Meeting, San Francisco, CA., Sept. 22-23, 1994.

Geothermal Research Council, Salt Lake City, Utah, Oct. 2-5, 1994. 
GSA Meeting, Seattle, WA, Oct. 26, 1994.

DOE Geothermal Program Review XIII, San Francisco, CA, March13-16, 1995.

Geothermal R\&D Workshop, Geothermal Energy Assoc., San Francisco, CA, July20-21, 1995.

User Interface Workshop on Parallel Programming Software (AAPSS), Santa Barbara, CA, July 22, 1995.

ACS National Meeting, New Orleans, La, March 24-28, 1996.

DOE Geothermal Program review XIV, San Francisco, CA, April9-10, 1996.

$30^{\text {th }}$. International Geological Congress, Beijing China (Z. Duan), August 4-14, 1996.

GRC Meeting, October, 1996.

DOE Geothermal Program Review, San Francisco, March 25, 1997.

DOE-BES review, Oak Ridge, April 27-30, 1997.

GRC meeting, San Franciso, April 30 - May 1, 1997.

DOE field trip and workshop, Dixie Valley, NV, May, 1997.

7th. Annual Goldschmidt Conference, Tuson, Arizona, June 2-6, 1997.

DOE Dixie Valley meeting, Reno NV, Aug. 26-27.

Asian Fluid Inclusion Conference (Z. Duan), Sept. 24-Oct. 15, 1997.

Calorimetry Conference, Midland, Michigan, August 9-15, 1998.

Environmental Chemistry Conference, UCSD, 1998.

Geothermal DOE Program Review XVI, Berkeley CA, April 1-2, 1998.

Goldschmidt Conference, Toulouse, France, Aug.30-Sept.3, 1998.

PACROFI VII, Pan American Current Research on Fluid Inclusions, Las Vegas, NV, June 1-4, 1998.

U.C. Berkeley, Earth Resources Center, Prof. Bremhall, December 9, 1998.

\section{Selected Publications During Grant Period:}

Moller, Weare, Duan and Greenberg (1994) "User friendly models for chemical and thermophysical properties of geothermal fluids." DOE Proceedings of the Geothermal Program Review XII, April.

Moller, Weare, Duan and Greenberg (1994) DOE workshop Tutorial: "Chemical models for optimizing geothermal power plant performance." pp. 57.

Felmy and Weare (1995). "The development and application of aqueous thermodynamic models: The specific-interaction approach". Chemical Equilibrium and Reaction Models, Soil Science Society of America, Special Publication 42, 31-52.

Duan, Moller and Weare (1995). "Molecular dynamics equation of state for nonpolar geochemical fluids." Geochim. Cosmochim. Acta 59, No. 8, 1533-1588.

Duan, Moller and Weare (1995). "Molecular dynamics simulation of water properties using the RWK2 potential; From clusters to bulk water." Geochim. Cosmochim. Acta 59, No. 16, 32733283. 
Duan, Moller and Weare (1995). "Equation of state for the $\mathrm{NaCl}-\mathrm{H}_{2} \mathrm{O}-\mathrm{CO}_{2}$ system: Prediction of phase equilibria and volumetric properties." Geochim. Cosmochim. Acta 59, No. 14, 2869-2882.

Duan, Moller and Weare (1995). Comment on "Measurement of the PVT properties of water to $25 \mathrm{kbars}$ and $1600^{\circ} \mathrm{C}$ from synthetic fluid inclusions in corundum" by J.P. Brodholt and B.J. Wood." Geochim. Cosmochim. Acta 59, No. 12, 2639.

Moller, Weare, Duan and Greenberg (1995). "Advanced modeling technology for predicting geothermal brine/gas chemistry." DOE Proceedings of Geothermal Program Review XIII.

Ren et al. (1995) "Characteristics of the hydrothermal system of the porphyry copper (gold) deposits at Shaxi, Eastern China." Water-Rock Interaction (ed . Kharaka and Chudaev), 683685.

Duan, Moller and Weare (1996). Prediction of solubility of $\mathrm{H}_{2} \mathrm{~S}$ in $\mathrm{NaCl}$ aqueous solutions-An equation of state approach. Chemical Geology 130, No. 1-2, 15-20.

Duan, Moller and Weare (1996). A general equation of state for supercritical fluid mixtures and molecular dynamics simulation of mixture PVTX properties. Geochim. Cosmochim. Acta 60, No. 7, 1209-1216.

Duan, Moller and Weare (1996). Equation of state for the $\mathrm{NH}_{3}-\mathrm{H}_{2} \mathrm{O}$ system. J. Solution Chemistry 25, No. 1, 43-50.

Duan, Moller, DeRocher and Weare (1996). Prediction of boiling, scaling and formation conditions in geothermal reservoirs using computer programs TEQUIL and GEOFLUIDS. Geothermics 25, No. 6, 663-678.

Moller, Weare, Duan, Greenberg (1996). Chemical models for optimizing geothermal energy production. DOE Proceeding of Geothermal Program Review IV.

Lubin and Weare (1998). "First principles simulation of aluminum solvation in aqueous solutions." Minerol. Mag. 62A, (Part 3) 915.

Mфller., Greenberg and Weare (1998). "Computer modeling for geothermal systems." Transport in Porous Media 33(1-2), 173-204.

Weare, Duan and Mфller (1998). "Supercritical thermodynamics and fluid/fluid phase coexistence in thermodynamic systems." Minerol. Mag 62A, (Part 3), 1637.

Mфller, N., Weare, J., Greenberg J. and Duan Z (1998). "Chemical Models for Optimizing Geothermal Energy Production." DOE Geothermal Program Review XVI, April 1-2, San Francisco, CA. 


\section{REFERENCES:}

Anderko A. and Pitzer K. (1993). Geochim. Cosmochim. Acta, 57, 1657-1680.

Dimitrelis D. and Prausnitz J. (1986). Fluid Phase Equilibria, 31, 1-21.

Duan Z., Møller N., and Weare J. H. (1992a). Geochim. Cosmochim. Acta 56, 2605-2617.

Duan Z., Møller N., and Weare J. H. (1992b). Geochim. Cosmochim. Acta 56, 2619-2631.

Duan Z., Møller N., Greenberg J.P., and Weare J. H. (1992c). Geochim. Cosmochim. Acta, 56, 1451-1460.

Duan Z., Møller N., and Weare J. H. (1992d). Geochim Cosmochim Acta 56, 3839-3845.

Duan Z., Møller N., and Weare J. H. (1995a). Geochim Cosmochim Acta 59, 1533-1588.

Duan Z., Møller N., and Weare J. H. (1995b). Geochim. Cosmochim. Acta, 59, 2869-2882.

Duan Z., Møller N., and Weare J. H. (1995c). Geochim Cosmochim Acta 59, 3273-3283.

Duan Z., Møller N., and Weare J. H. (1995d). Geochim Cosmochim Acta 59, 2639.

Duan Z., Møller N., and Weare J. H. (1996a). Geochim. Cosmochim. Acta, 60, 1209-1216.

Duan Z., Møller N., and Weare J. H. (1996b). J. Soln. Chemistry 25, 43-50.

Duan Z., Møller N., and Weare J. H. (1996c). Chemical Geology 130, 15-20.

Duan Z., Møller N., DeRocher T. and Weare J. H. (1996d). Geothermics 25, 663-678.

Harvie C. E and Weare J. H. (1980). Geochim Cosmochim Acta 44, 981-997.

Harvie C.E., Møller N. and Weare J.H. (1984). Geochim. Cosmochim. Acta, 48, 723-751.

Greenberg J. and Møller N. (1989). Geochim Cosmochim Acta 53, 2503-2518.

Møller N. (1988). Geochim. Cosmochim. Acta 52, 821-837.

Mфller N., Greenberg, J. and Weare J. (1998). Transport in Porous Media 33 (1-2), 173.

Pitzer K. (1987). Reviews in Minerology, chapter 4, BookCrafters, Inc., 96-142.

Pitzer K., and Peiper J.C. and Busey, R.H. (1984) J. Phys. Chem. Ref. Data 13, 1-94.

Spencer R.J., Møller N. and Weare, J.H. (1990). Geochim. Cosmochim. Acta, 54, 575-590.

Weare J. H. (1987). Reviews in Mineralogy 17, 143-176. 